\title{
GEOCHEMICAL TRANSFORMATION OF PEAT-PODZOLICAND PEAT SOILS OF THE MIDDLE TAIGA OF WESTERN SYBERIA UNDER THE IMPACT OF TECHNOGENICHYDROCARBONS
}

\author{
DOI: https://doi.org/10.18509/AGB.2020.17
}

UDC: 504.12:502.521]:662.765.4(285.3)(571.1)

\section{Elena Dvurechenskya}

Moscow City Branch of the Russian Geographical Society, Russian Federation

corresponding author: navrodskaya@gmail.com

\begin{abstract}
In the physical and geographical respect West Siberian Plain is a huge swamp system which creates, to a great extent, an environment for pollutant preservation rather than removal the pollutants from the landscape. The maximum level of pollution with the minimum possibility of its removal causes significant environmental problems in the region. Mid-taiga landscapes occupying territories in the middle reaches of the Ob experience the highest technogenic load of oil production among the West Siberian landscapes. At various oil spills within the upper bogs and forests, a landscape-geochemical survey was performed both in the area and soil sections. The following parameters were determined in soil samples: $\mathrm{pH}$, organic carbon, ion-salt composition. Detailed maps of dispersion halos were developed. This paper helps to expand ecological information of the pollutant-soil-time-effect system and can be the basis for the classification of mid-taiga landscapes by their resistance to hydrocarbons.
\end{abstract}

Keywords: oil pollution, soil salinization, West Siberian, technogenic hydrocarbons, peat soils.

\section{INTRODUCTION}

West Siberian Plain is a huge swamp system which creates, to a great extent, an environment for pollutant preservation rather than removal the pollutants from the landscape. The maximum level of pollution with the minimum possibility of its removal causes significant environmental problems in the region. Mid-taiga landscapes occupying territories in the middle reaches of the $\mathrm{Ob}$ experience the highest technogenic load of oil production among the West Siberian landscapes.

This paper is aimed at identifying differences in the

\section{LOCATION}

The study area is in the central part of the West Siberian Plain in the interstream tributaries of the river Ob - the Bolshoy Volysyakh and Malyi Salym. The relief of the Middle $\mathrm{Ob}$ region is water-glacial, laky, alluvial-laky lowland plains, dissected floodplains. Deposits of water accumulation take part in the formation of thes plains - they are of response to hydrocarbon pollution of the forest and marsh ecosystems of the middle taiga. The results described in this paper are based on the personal research of the author. The research works were conducted by the author in 2009, 2010, 2012 and 2017 as part of the projects of the Geography Department of Moscow State University and Yugor State University, as well as environmental programs of NPC "Monitoring" company (city of Khanty-Mansiysk).

water-glacial, laky, laky-alluvial and swamp origins (Karavaeva, 1982). The quaternary deposits in the limits of the research area are represented by holocene, alluvial, fine-grained sands with thickness from 8 to $15 \mathrm{~m}$ and pleistocene lakyalluvial loam with lenses of loamy light sand. In respect of geomorphologic regionalization, this 
area is referred to laky-alluvial plains and terraces (Atlas.....2004). The average absolute heights vary from 30 to $80 \mathrm{~m}$. The angles of the surface slopes range from 0.5 to 1.5 degrees, the watermarks reach $40 \mathrm{~m}$. Swamp formation plays a major role in the formation of the microrelief. Swamp areas occupy about $40 \%$ of the territory of the licensed land and are represented by ridge-laky or ridge-hollow complexes, framing the lakes, which higher in the relief are replaced by ridge swamps with oppressed pine forest. The shrub layer is dominated by Cassandra, wild rosemary, cranberry, cowberry and cloudberry. The mushed moss is represented by common in the Arctic and boreal zones species of sphagnum. The polydominant forest communities of the greenmoss group occupy about $30 \%$ of the entire area of studies. In addition to the fundamental association - cedar forest of short grass pleurocarpous moss, they are represented by small-leaf pleurocarpous moss associations of various development stages. The height of the tree layer in the limits of the licensed land is $17-21 \mathrm{~m}$, while the stem diameter is $20 \mathrm{~cm}$, distance between the trees is 4-5 $\mathrm{m}$. In the woody composition of the upper layer quiet often in small groups or single trees can be found overmatured birch and aspen trees.

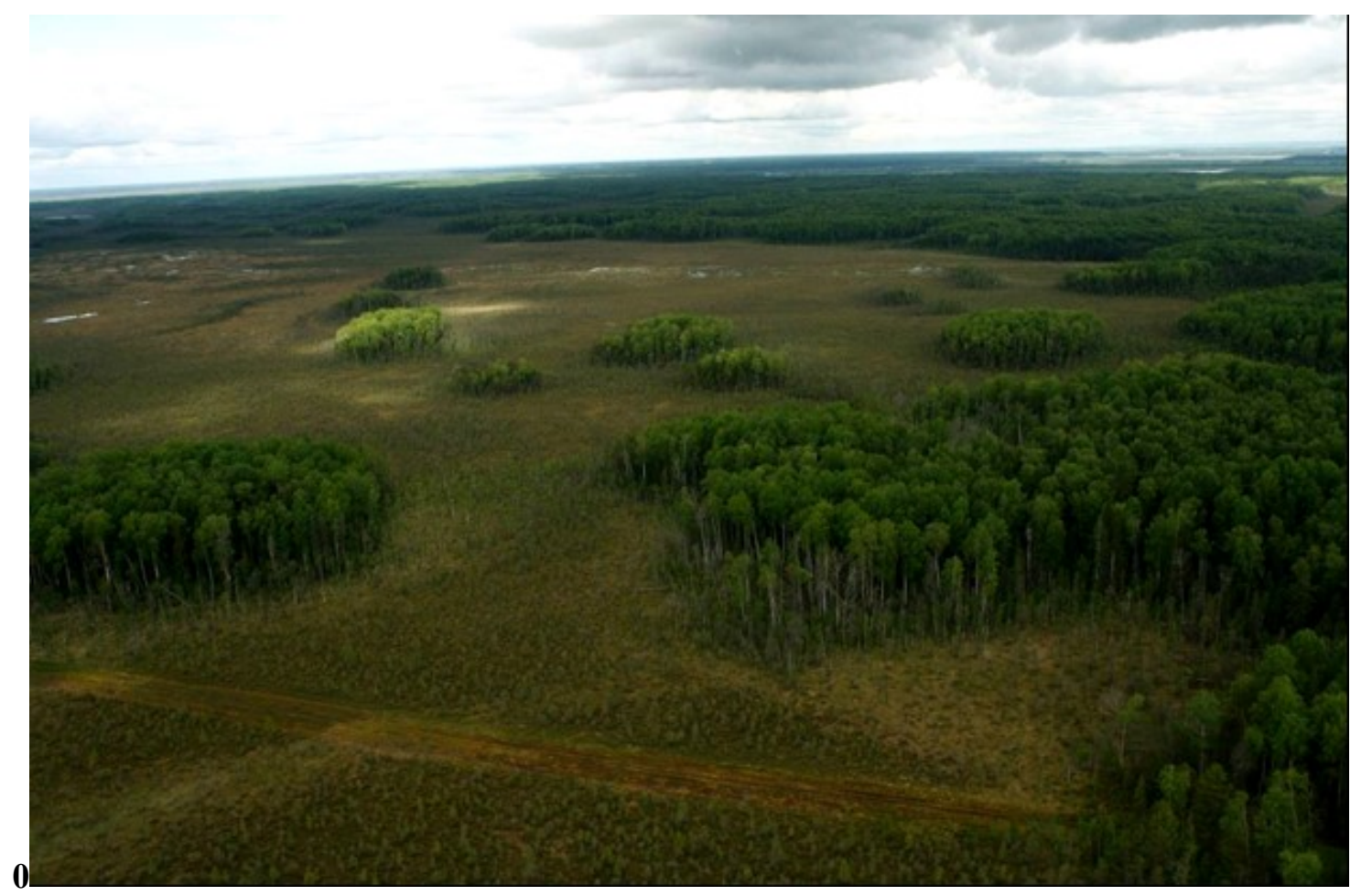

Figure 1. Landscapes of the research site (photo by the author).

The geochemical landscapes of the studied area (pic.1) belong to the acid gley taiga (Perelman and Kasimov, 1999). The biomass of the tree layer here reaches $2000 \mathrm{c} / \mathrm{h}$, and of the moss layer up to 50 $100 \mathrm{c} / \mathrm{h}$. Decomposition of the organic residues proceeds slowly, thick underlayer accumulates and the "underlayer litter index" reaches several tens. In the subordinate swamp landscapes the N, P, K

\section{METHODS AND AIM OF STUDY}

The soil cover of the research site is highly complex due to differences in the nature of the quaternary sediments and, therefore, in the conditions of drainage, soils of the relatively drained areas are cycle is greatly slowed down because these elements are actively absorbed by plants. The formed complex organic compounds turning into peat later, in fact do not participate in the beak of this landscape. In swamps and taiga landscapes oxygen deficiency is observed and $\mathrm{Fe}+$ и $\mathrm{H}+$ appear to be excessive.

represented by peat-podzolic varieties, and peatlike organogenic soils are common within swamp ecosystems. Peat-podzolic soils are formed under coniferous forests, mainly on the holocenic loamy 
and clay deposits, less often on dense bedrocks. The conditions of their formation are characterized by periodic water saturation of the upper part of the profile: before snow melting in spring and in autumn before setting the snow cover. Soils have the following profile structure:

- A0 - poorly decomposed forest underlay with thickness of $5-10 \mathrm{~cm}$ gradually moving into A0A1 horizon, highly enriched with organic residues or replaced by a strongly colored humus horizon A1A2 with thickness of $23 \mathrm{~cm}$;

- A2 - podzol horizon with thickness of 2-15 cm of whiteish or whitish-grey coloring, platy, layered-platy, scaly or leafy structure;

- A2B - multicolored transitional horizon; it alternates sections of horizons $\mathrm{A} 2$ and $\mathrm{B}$. Horizon areas A 2 are formed in leakages, pockets, wedges with thickness of 10-50 cm;

- B - illuvial horizon, the most brightly colored in the profile, reddish-black, ochre-brown shades of coloring, very dense, nutty, lumpy-nutty structure, which is enlarged to the prismatic structure. The cracks and faces of the structural units contain abundant whitish powder, brown glossy sagging cover, the horizon gradually transforms into a parent rock at the depth of 50$120 \mathrm{~cm}$.

These soils are characterized by acidic and weakacid reaction, enrichment of the upper part of the profile with silica quartz, impoverishment of primary and clay minerals, sesquioxides and sludge, e in the desilting horizon emerging of easily mobilized forms of iron. The salt content is close to $0 \%$ throughout the profile. The organic carbon content is dramatically differentiated along the profile, increasing in the underlayer. $\mathrm{Al}$ and $\mathrm{H}$ predominate among the, among $\mathrm{Cl}$ cations.

The high complexity of swamp ecosystems also impacts the nature of the swamp soil cover. [2]. There can be observed frequent changes in moss thickness, its decomposition, water cutting, botanic content. According the modern classification [3] these differences result in separation of two subtypes of peat soils - typical, which thickness exceeding $1 \mathrm{~m}$ and peat-gley soils, which are underlaid with gley mineral mass at the depth of 50 to $100 \mathrm{~cm}$. They also led to identification of peat soils on the variety level according to their thickness and decomposition degree of peat. Peat typical organogenic soils are formed within swamp ecosystems, which occupy huge areas in the middle taiga of Western Siberia. On the research site, ryam and ridge-hollow swamps are widely spread. The swamps of the ryam type of soils occupy convex peaks within the interstream areas and are characterized by pine-shrub-sphagnum vegetation on the top of peat soils. In summer they have active peat layer without gravity moisture and with the average ground water level $20-50 \mathrm{~cm}$. This type of soils is characterized by acid environment reaction along all the profile and low salt content. The ionand-salt complex is dominated by $\mathrm{Al}, \mathrm{H}, \mathrm{Cl}$. Organic carbon content is from $20 \%$ to $30 \%$ evenly increasing to the bottom of the profile.

The ridge-hollow swamps develop on homogeneous slope surfaces and are distinguished by a specific meso relief in the form of ridges and swampy hollows. The process of their formation includes participation of watercourses (peat rivers, streams) which implement the drainage and provide different plant nutrition. The mechanism of ridge and swampy hollow formation, described by I.D. Bogdanovska-Gyenef (1936), is based on the phytocenotic interaction of plants. According to this information, water going through thick root system of plants is impoverished by salts and oxygen. On the sides of the plant water does not undergo such changes and that is why the plant spreads its new shoots there. This is how a primary ridge, elongated perpendicular the water flow, is formed, and it gradually expands to the side from which the water comes. Then this primary differentiation is enhanced due to different frost penetration in winter.

Vegetation cover of ridge-hollow swamps is differentiated into swampy hollow and ridge plants. Pine grows on the ridges with the height of 4-5 m and diameter $8-10 \mathrm{~cm}$. The shrub layer is dominated by blueberries and cowberries, a single dwarf birch is found. Vaginal cotton grass grows on the outskirts. Woody and shrub layers are absent within the area of swampy hollows. Sedge, andromeda and sundew prevail in the grassy layer. Sphagnum mosses form a dense carpet on the ridges and within the swampy hollow area they die under flooding conditions by $30-40 \%$.

Soils of ridge-hollow swamps are not much different from ryam swamp soils in their chemical characteristics. The differences are mainly in the degree of hydro morphism. The soils of ridge- 
thollow swamps are more hydromorphic and have acid environment reaction. $\mathrm{pH}$ values range from 4.3 to 4.6 . The salt content slightly decreases to the bottom of the profile from 0.01 to $0.005 \%$. The organic carbon content is maximum in the upper part of the profile (30\%).

Within the research site there is a licensed oil production site, Prirazlomnoye, the industrial operation of which began in 1986 by "Pravdinskneft" company and it has been developed and operated by 'Yuganskneftegaz' since 1998. Thus, for more than 30 years there has been an intensive technogenic impact on this area. Explored oil reserves at the site amount to 658.8 million tons, extracted 218.2 million tons. According to the data of 2018, the number of the pumping sites in the research area reaches 109 , the total number of oil wells -760 . A commercial oil accounting station operates at the oil pumping site. The total length of the pipelines is $1462.2 \mathrm{~km}$. The number of static sources of pollutant emissions is 839 which is estimated to be 195.9 thousand tons per year. An average of about 50 emergency situations a year are recorded at the licensed site. On average, during accidents at this field, 25.4 tons of pollutants get in the landscapes, of which 2.9 tons of produced water and 22.5 tons of oil products which are the main suppliers of technogenic hydrocarbons and readily soluble salts. The area of contaminated lands during accidents is 2.39 ha. There about 50 oil wells on the area of $1 \mathrm{~km}, 2.3 \mathrm{~km}$ of pipelines and $2 \mathrm{~km}$ of roads, which defines a significant technogenic pressure. The main sources of technogenic hydrocarbons in the Prirazlomnoye licensed area are oil pipelines and cluster sites. We will consider differences in the geochemical transformation of soils under different kinds of impact. The field work was conducted in August of

\section{RESULTS}

The impact of emergency oil spills from oil pipelines is associated with technogenic flows into natural environment, the main component of them is oil. This process results in the change of the geochemical background of the territory, namely, he amount of carbon in soils, which is identidied in oil-contaminated soils as an indicator of the total content of bituminous substances (oil products). In peat swamp upland soils there is virtually no impact of the surface slope on the spread of
2008 , in July 2009, 2010, 2012, 2017. In the process of the field work, route surveys and more detailed studies were conducted in the key areas with the help of the principle of priority study of disturbed and undisturbed wetland ecosystems within the licensed area using complex description of phases. The description points were laid along the route within swamp ecosystems of different types backgrounds undisturbed and with various kinds of technogenic impact within the oil field. A total of 88 points were laid. In the process of work, GPS coordinates were determined on each of them, a description of the general nature of the relief was done and the peculiarities of the meso- and microrelief were determined, also the description of the vegetation and soil sections by determining the soil profile type was done and the characteristics of its horizons were described, as well as the general description of swamp types was implemented.

The research points within the key area were laid from the accident point to its edge part. In addition, the background analogues of undisturbed territories were studied. Descriptions of the points were compiled by analogy with the descriptions of the route studies, also samples were taken (from each genetic horizon) and samples of ground waters [4]. Assessment of the geochemical transformation was carried out according to three main indicators: $\mathrm{pH}$, total organic carbon content for undisturbed soils, total amount of oil products for contaminated soil types, total content of readily soluble salts , and ionsalt composition was determined in the process of evaluating technogenic flows involving salts [1]. About 180 soil samples were analyzed and 620 samples were studied to be identified in the chemical analytical laboratories of the Geography Department of Moscow State University, Yugor State University and SIC "Monitoring.

pollutants. However, there are differences in the distribution between the soils of ryam and ridgehollow swamps.In the ridge-hollow swamps within the area of hollows, the decrease in concentrations occurs evenly and, as you move away from the source of pollution for $100 \mathrm{~m}$ varies from 3000 to 0 $\mathrm{mg} / \mathrm{kg}$, because the vertical-side directions of the swamp water movements prevail, they are caused by the surface slope within such swamps in 2-3 degrees (pic. 2). The ridges in such swamps act as a 
mechanical barrier, preventing the spread of the pollutant. Technogenic anomalies have a more local character within ryam swamps. Thus, concentration of technogenic hydrocarbons decreases in the distance of $20 \mathrm{~m}$ from the point of the pipe accident from 3000 to $200 \mathrm{mg} / \mathrm{kg}$. This can be explained by domination of vertical directions in swamp water movements in case ryam swamps are on the flat land. (pic. 3). A characteristic feature of emerging technogenic anomaly is the location of its center near the surface in the ridge-hollow and ryam swamps (Pictures 4 and 5), which is associated with the peculiarities of the pipeline laying in humid areas (at the depth of $50 \mathrm{~cm}$ ) $\mathrm{pH}$ values increase to 6.0-7.5 (compared to the background values 3.03.5) in both types of soils - ridge-hollow and ryam swamps (pic. 6 and 7). $\mathrm{pH}$ values gradually approach the background values when you move from the pollution source and already at the distance of about $70 \mathrm{~m} \mathrm{pH}-4.0$. The intensity of $\mathrm{pH}$ changes can be more than 1 unit per meter. At the bottom of the soil profile and as you move from the pollution source, alkaline-acid changes are less expressed.

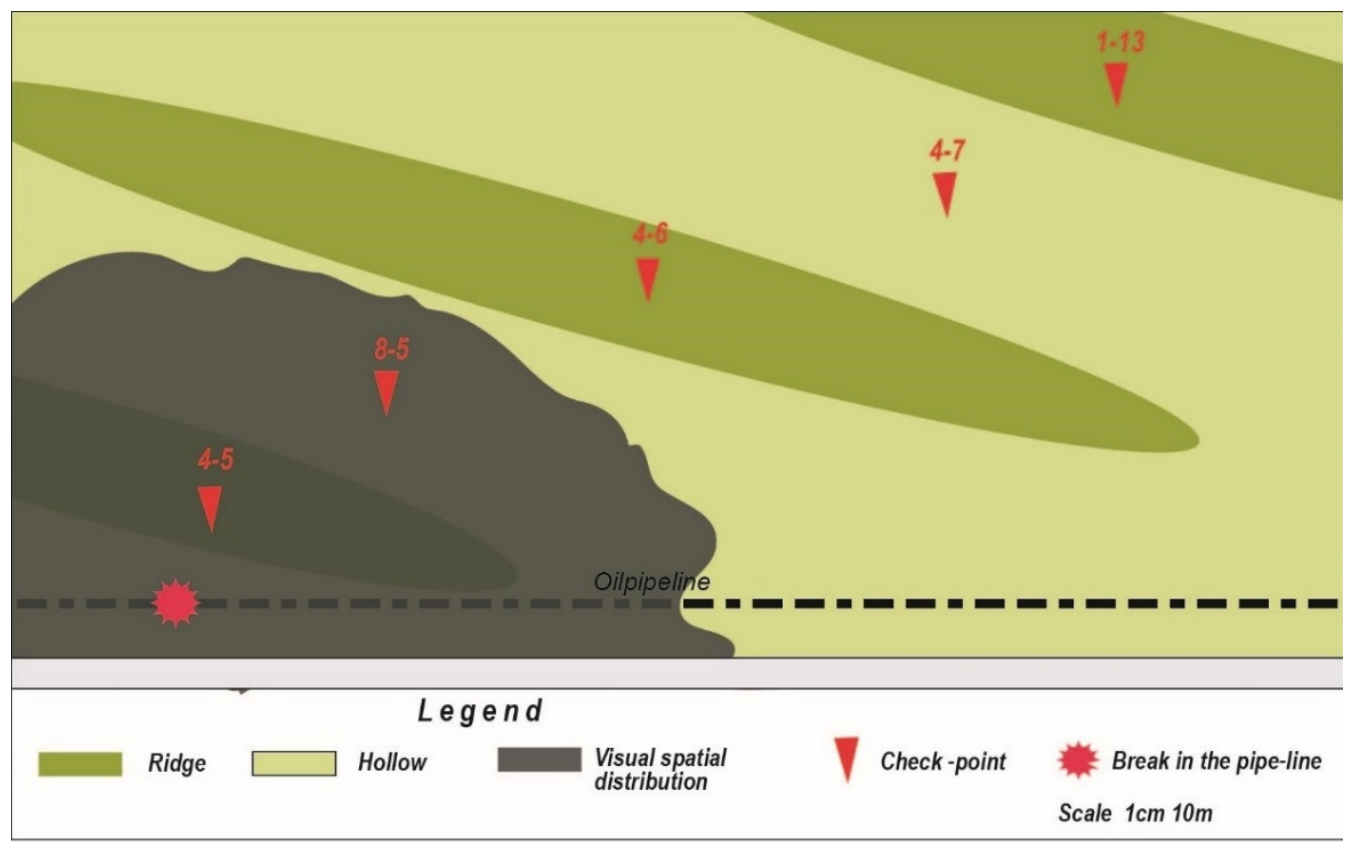

Figure 2. Spatial distribution of technogenic hydrocarbons in peat swamp upland soils of the ridge-hollow swamps when oil flows from the oil pipeline

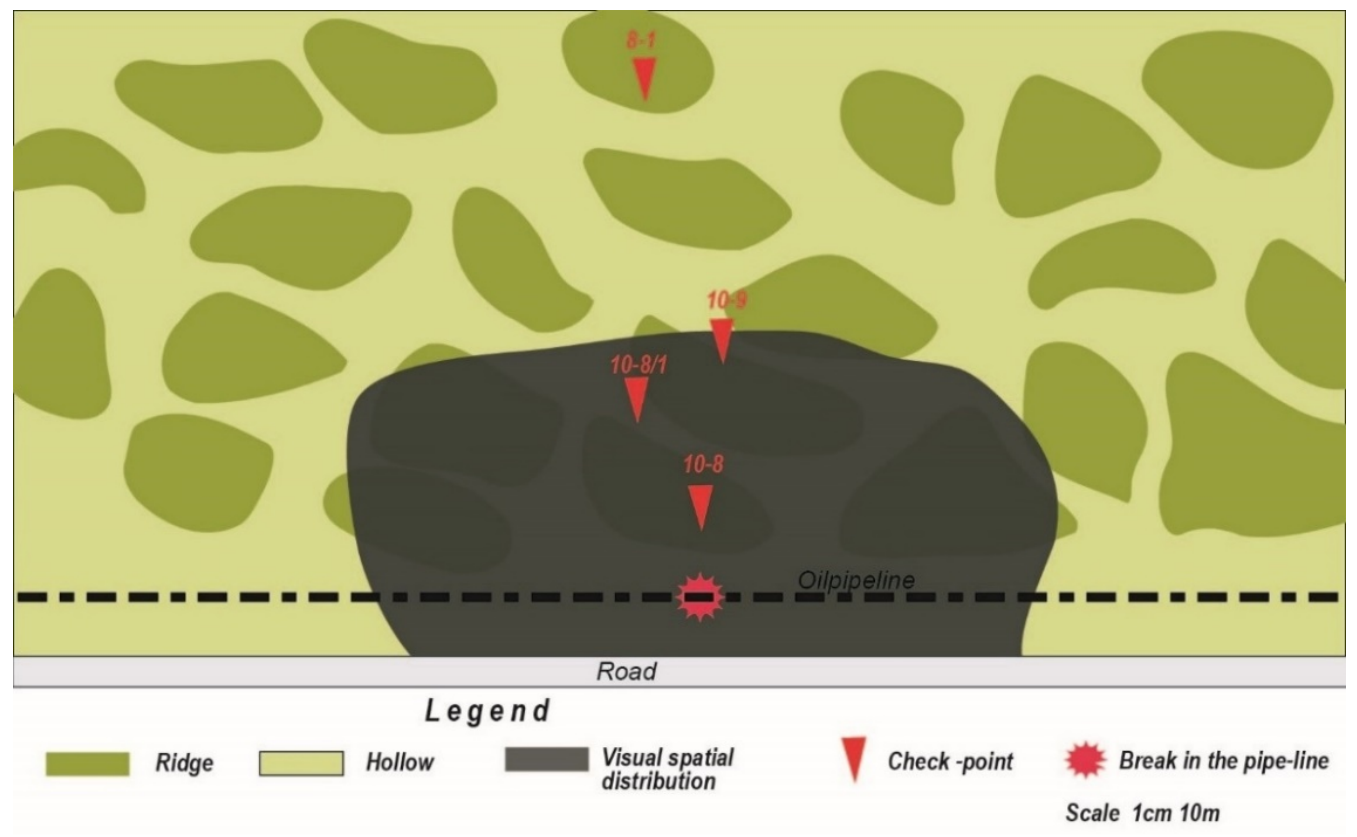

Figure 3. Spatial distribution of technogenic hydrocarbons in peat swamp 
upland soils of ryam swamps when oil flows from the oil pipeline.

\section{4-08 \\ Общее содержание битуминозных веществ, мг/кг}

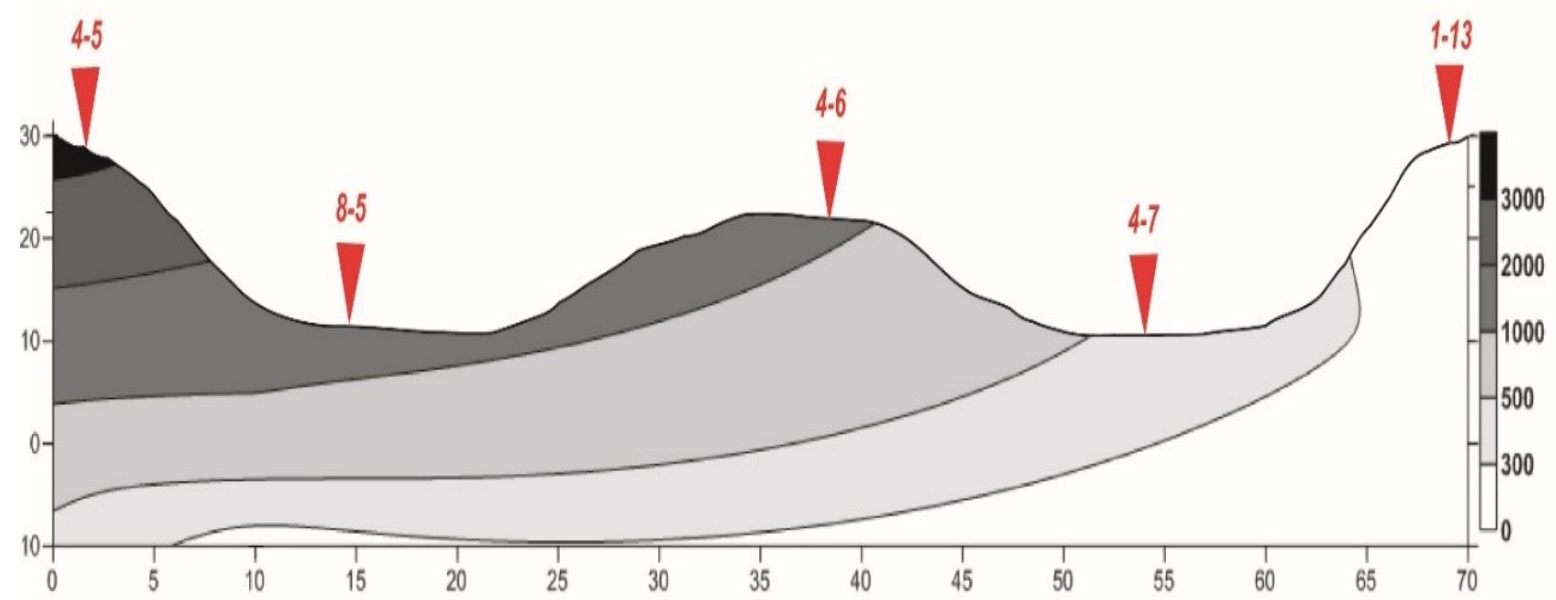

Figure 4. Lateral distribution (meters) of bituminous substances $(\mathrm{mg} / \mathrm{kg})$ on the catena in peat swamp upland soils of the ridge-hollow swamps when oil flows from the oil pipeline.

\section{Содержание битуминозных веществ, мг/кг}

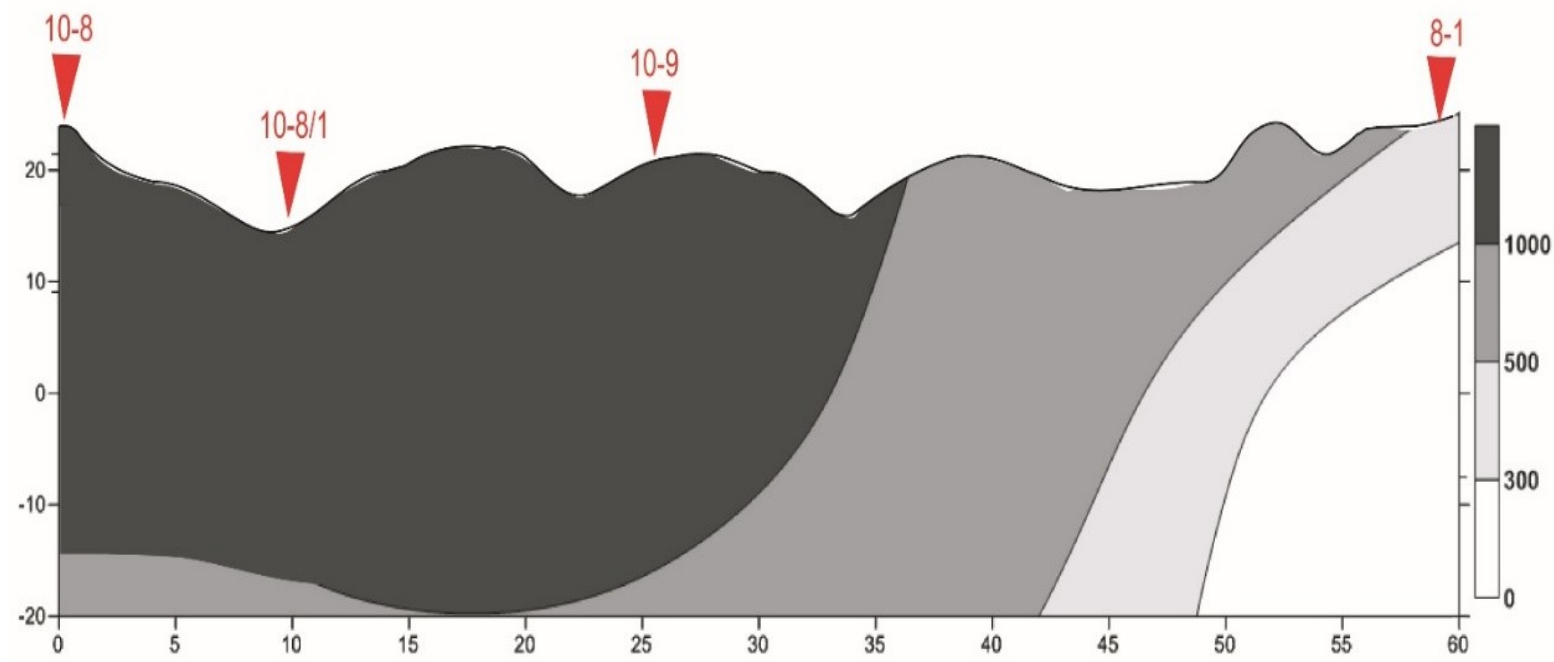

Figure 5. Lateral distribution (meters) of bituminous substances $(\mathrm{mg} / \mathrm{kg})$ on the catena in peat swamp upland soils of ryam swamps when oil flows from the oil pipeline.

The impact of accidental oil spills in the research area is accompanied by the entry into the soil profile of readily soluble salts, the content of which in the ultrafresh peat swamp upland soils increases to $2 \%$. In the vertical profile of organogenic peat soils contaminated with oil, intensive salinity can be traced to the depth of more than $30 \mathrm{~m}$. With a smaller absorbing capacity and a greater degree of hydro morphism, distributing more evenly the oil that is the supplier of salts, the soils of the ridge- hollow swamps are distinguished by the formation of salt accumulations at depth (Picture 8). The maximum salts in the sphagnum tow $(0-10 \mathrm{~cm})$ concentrates in the soils of ryam swamps.

Distribution of salts during oil pollution is opposite to alkalization of the medium. Alkalization of the environment coincides with oil accumulations in the soil profile, i.e. the basic alkalization mechanism under the impact of oil flows blocks soil exchange centers by hydrocarbons. 


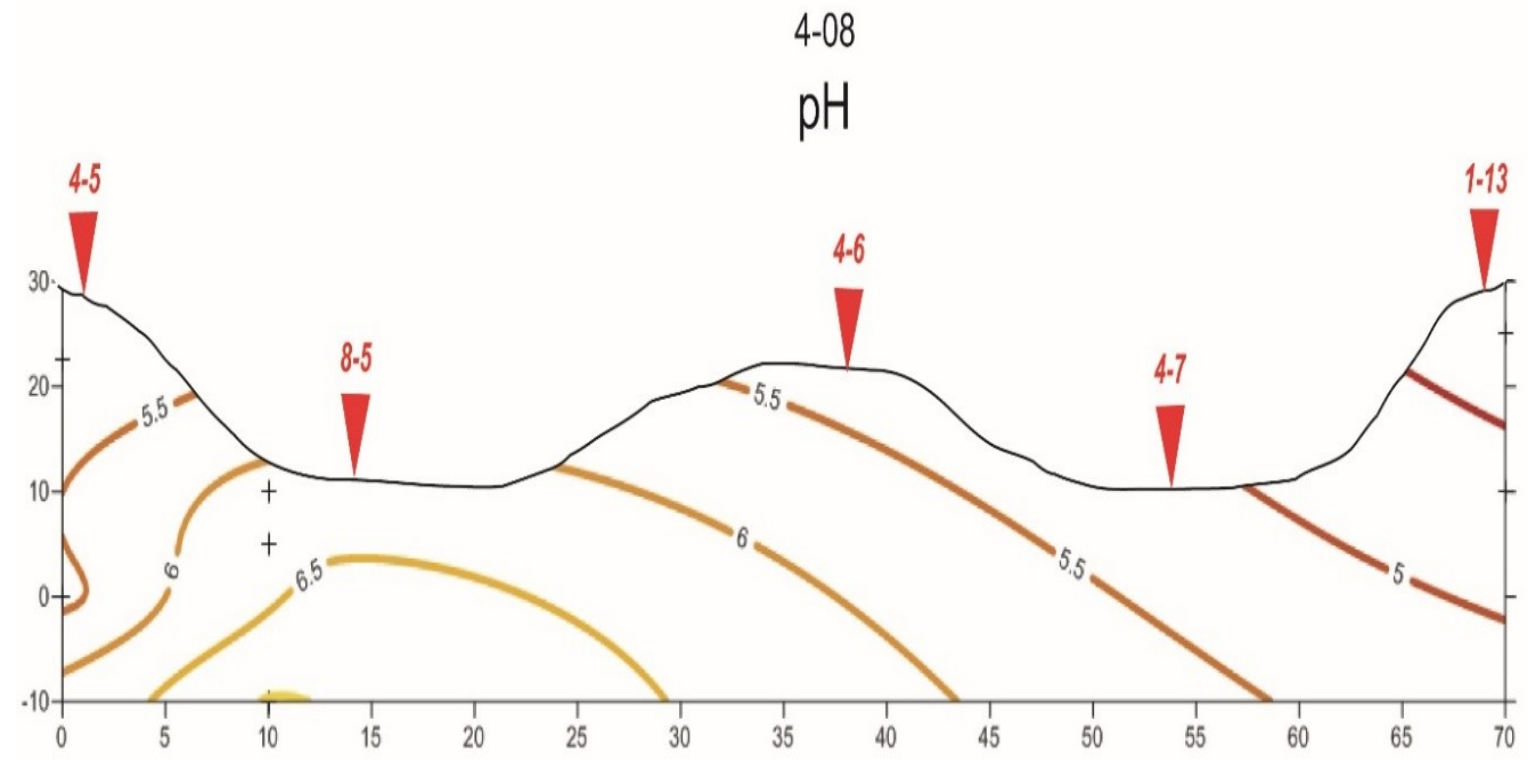

Figure 6. Change in $\mathrm{pH}$ values in peat swamp upland soils of ridge-hollow swamps during oil pipeline accidents

$\mathrm{pH}$

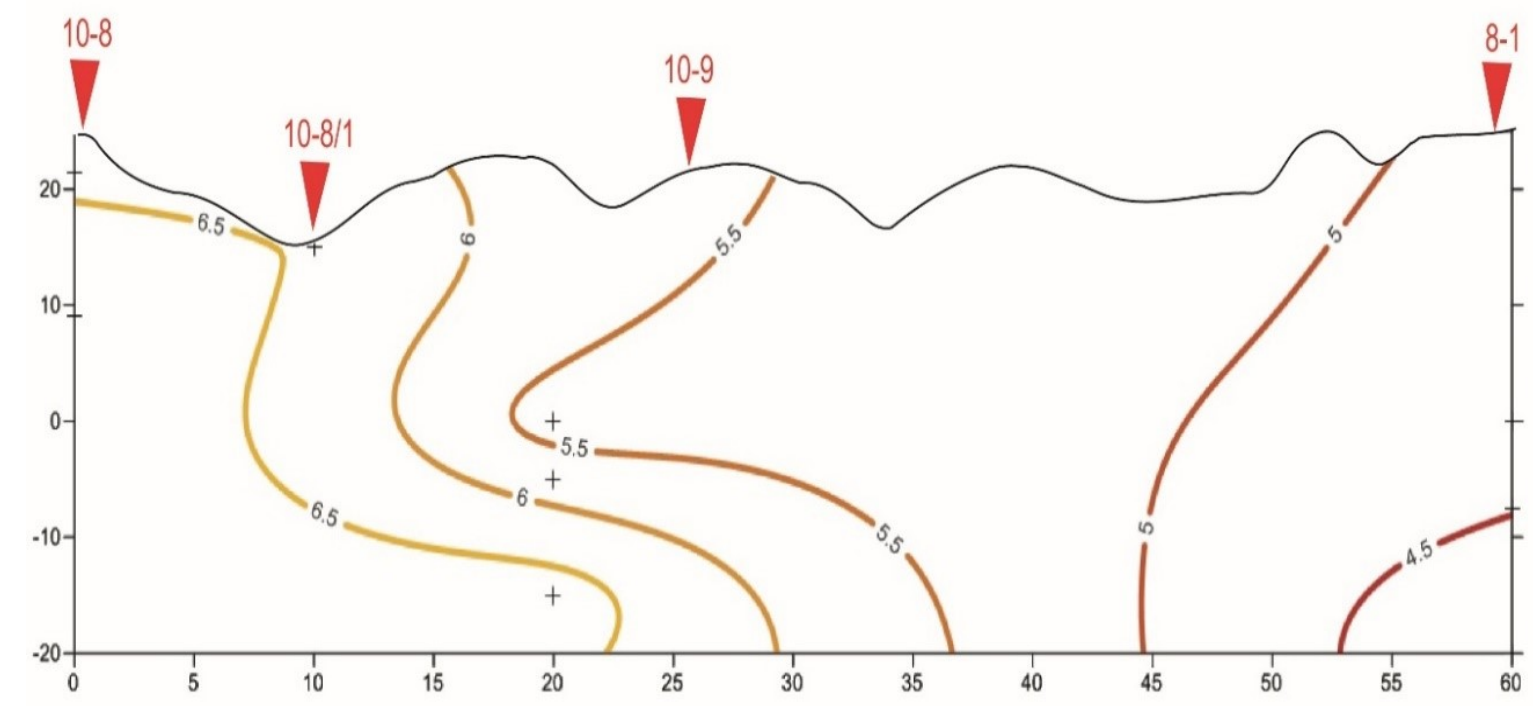

Figure 7. Change in $\mathrm{pH}$ values in peat swamp upland soils of ryam swamps during oil pipeline accidents.

In case of emergent oil spills from the pipeline, the surface slope plays the major role in spatial spreading of bituminous substances in peatpodzolic soils. The area of the Middle $\mathrm{Ob}$ region is characterized by a mosaic soil cover, in which peatpodzolic soils are replaced by peat swamp soils. This is associated with this area regression and the "advance" of swamps onto the forest. Thus, moving along the surface slope technogenic hydrocarbons, as a rule, accumulate in the swamps (pic. 10). In peat-podzolic soils the maximum content of bituminous substances reaches $10000 \mathrm{mg} / \mathrm{kg}$ and in peat swamp upland soils which received a flow of pollutants it reaches $100000 \mathrm{mg} / \mathrm{kg}$ (pic. 11). 

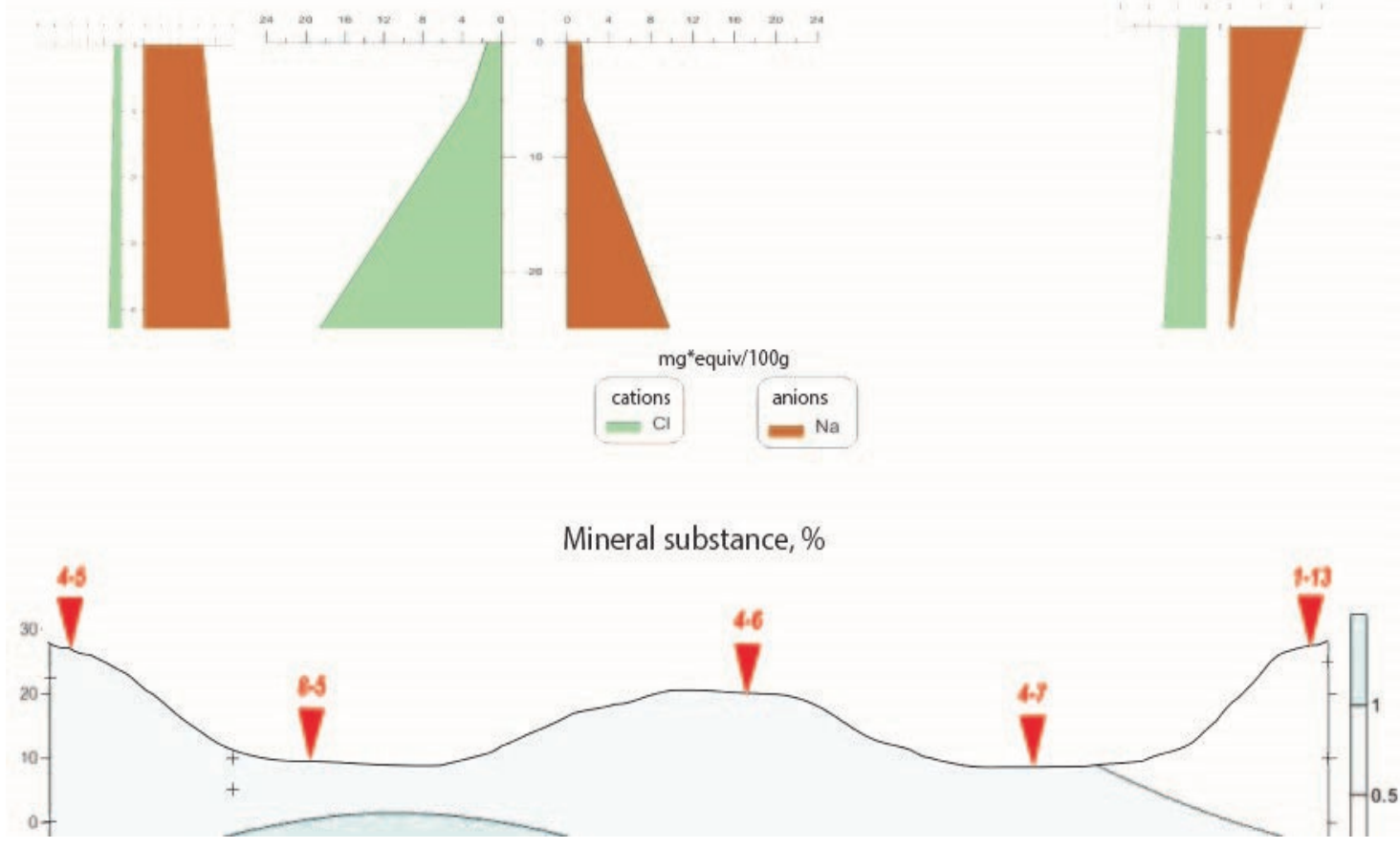

Figure 8. Change in the content of readily soluble salts in peat swamp upland soils of ridge-hollow swamps in case of oil pipeline accidents.

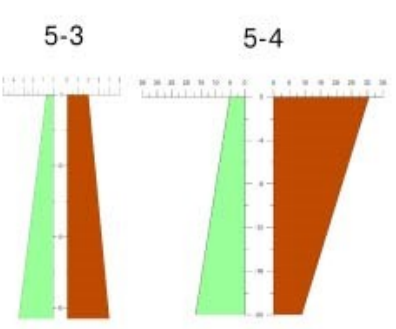

$5-6$

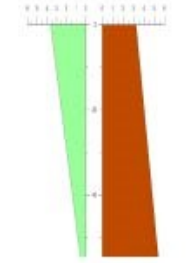

cations anions
$8-1$

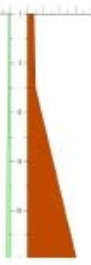

$\mathrm{mg}^{*}$ equiv/100g

Mineral substance, $\%$

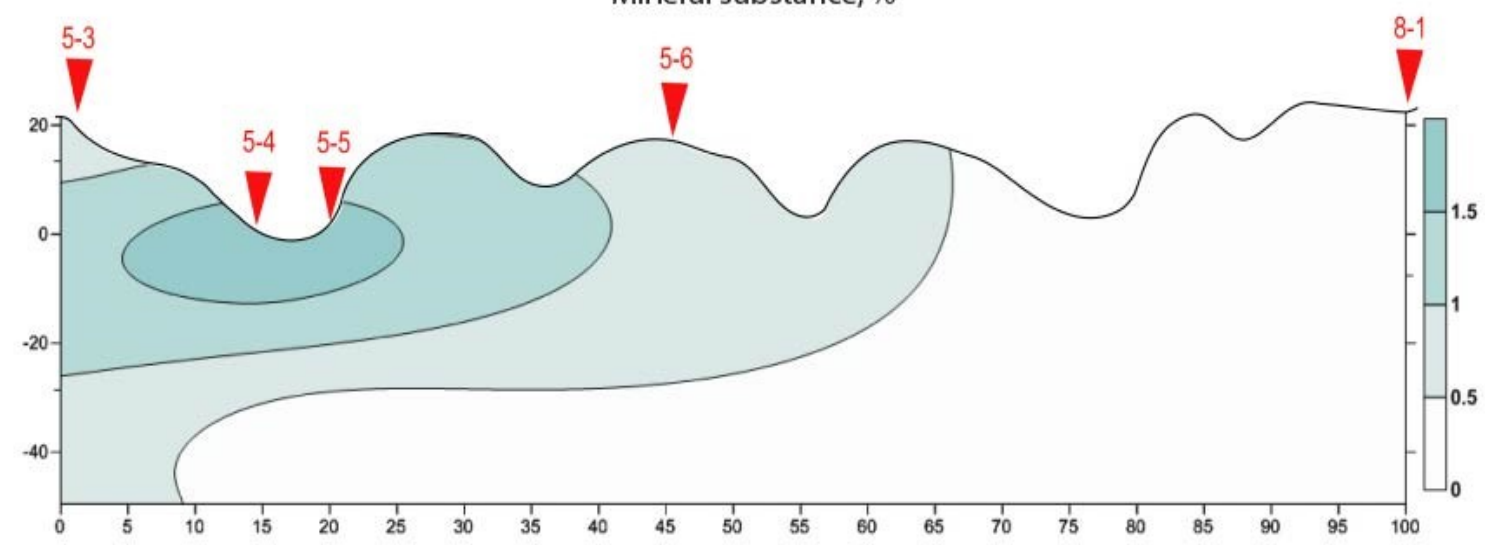

Figure 9. Change in the content of readily soluble salts in peat swamp upland soils of ryam swamps in case of oil pipeline accidents. 


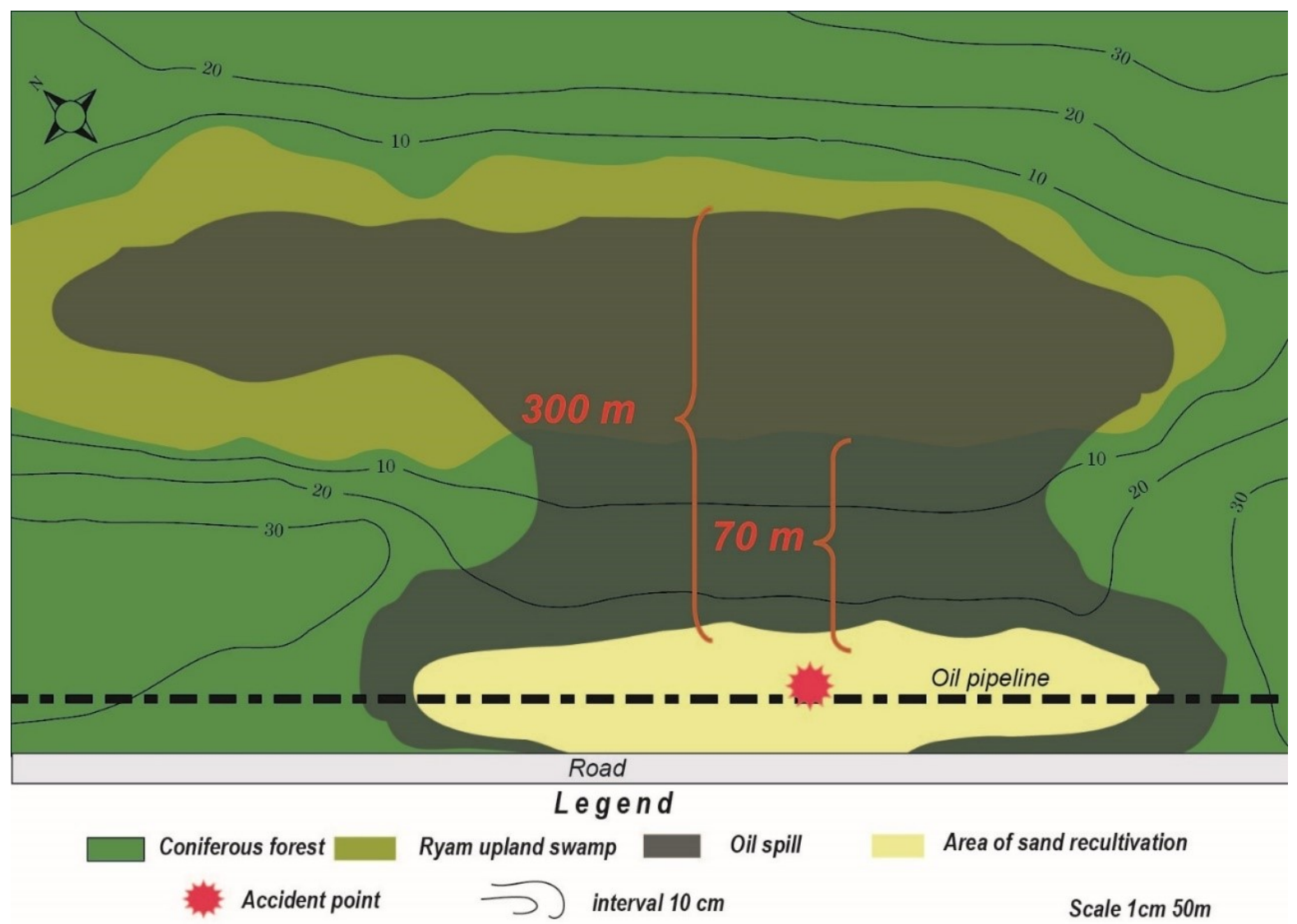

Figure 10. Spatial distribution of technogenic hydrocarbons in peat-podzolic soils when receiving oil from oil pipelines.

The maximum content of bituminous substances is observed in the upper soil layer $(0-10 \mathrm{~cm})$. The inter soil pollution by oil products in peat-podzolic soils is caused by seepage of pollutants, received during the oil spill (pic. 11). Pipelines in forest areas are laid at a greater depth than within swamp complexes. Therefore, the source of pollutant inflow is located at a greater depth when accidents happen. Changes in soil properties begin after the primary distribution which results in the change of acid-core conditions. In peat-podzolic soils alkalization process takes place. $\mathrm{pH}$ values increase to 5.5 in the root-inhabited layer compared to the background values 4.5 . With depth $\mathrm{pH}$ values reach the background values, for instance, at a depth of 40 $\mathrm{cm}$ values of 4.6-4.5 are defined. Picture 12 shows that swamp soils (points 5-7, 5-8) are alkalinized much more strongly, since they receive more pollutant and have a larger sorption capacity compared with peat-podzolic soils (points 5-4, 55).Location of technogenic salt accumulations gravitates to the groundwater level (pic. 12). The maximum salt content shifts to the bottom of the profile to the depth of $50-60 \mathrm{~cm}$ in peat-podzolic soils, and in peat swamp soils to the depth of $20 \mathrm{~cm}$, the ion-salt composition changes. Sodium and chlorine appear among atypical ions. The sodium content reaches $10-12 \mathrm{mg}$ *equiv/100 gr (in peatpodzolic soils) and $20-30 \mathrm{mg}^{*}$ equiv/100gr (in swamp soils); chlorine content is 6-8 $\mathrm{mg} *$ equiv/100gr and 20-50 $\mathrm{mg}$ *equiv/100gr respectively (pic. 12). In peat swamp soils saturated with $\mathrm{H}$ and $\mathrm{Al}, \mathrm{Na}$ and $\mathrm{Cl}$, it is difficult to displace hydrogen and aluminum from SNC organic components compared with mineral components which provides an increased content of readily soluble salts in peat swamp soils compared with peat-podzolic soils. 


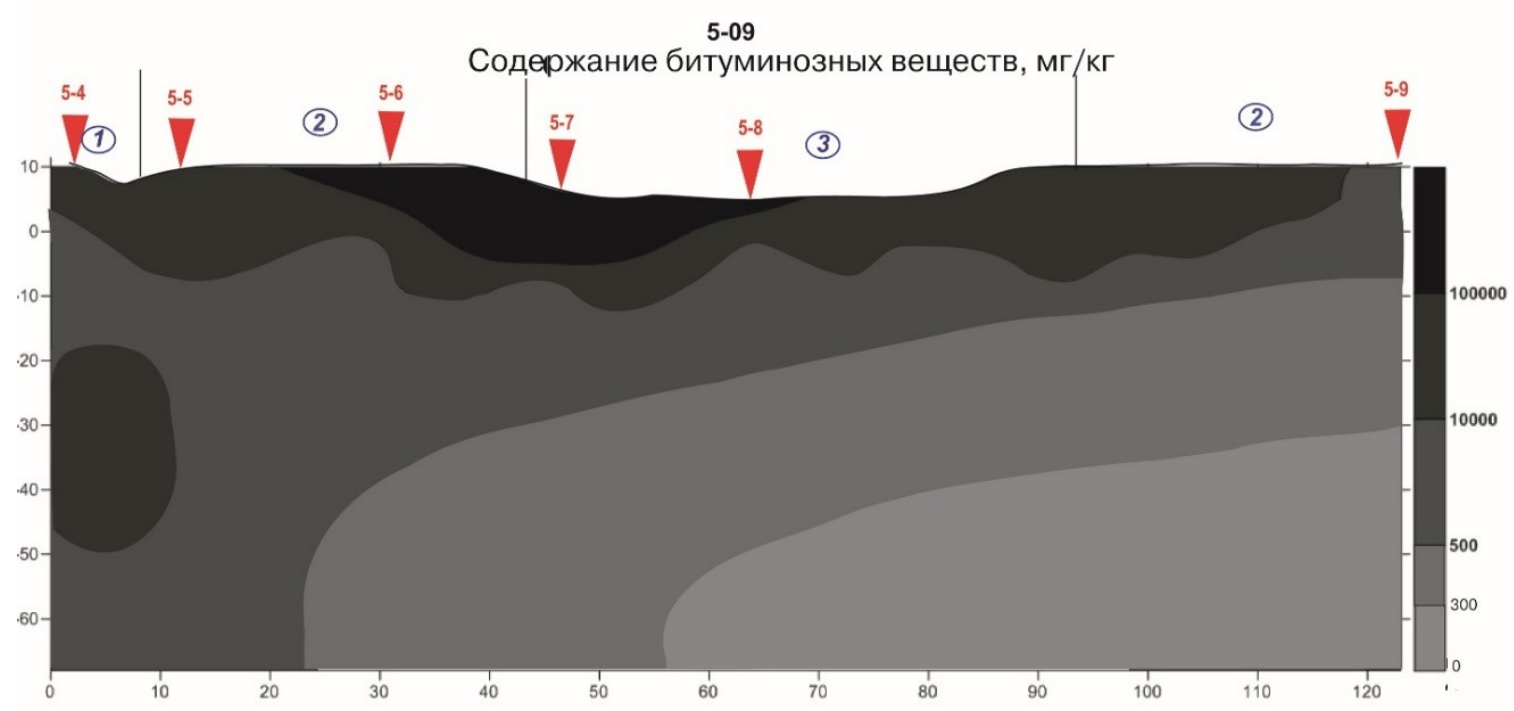

Figure 11. Lateral distribution of bituminous substances along the catena upon receipt of oil from the oil pipeline.

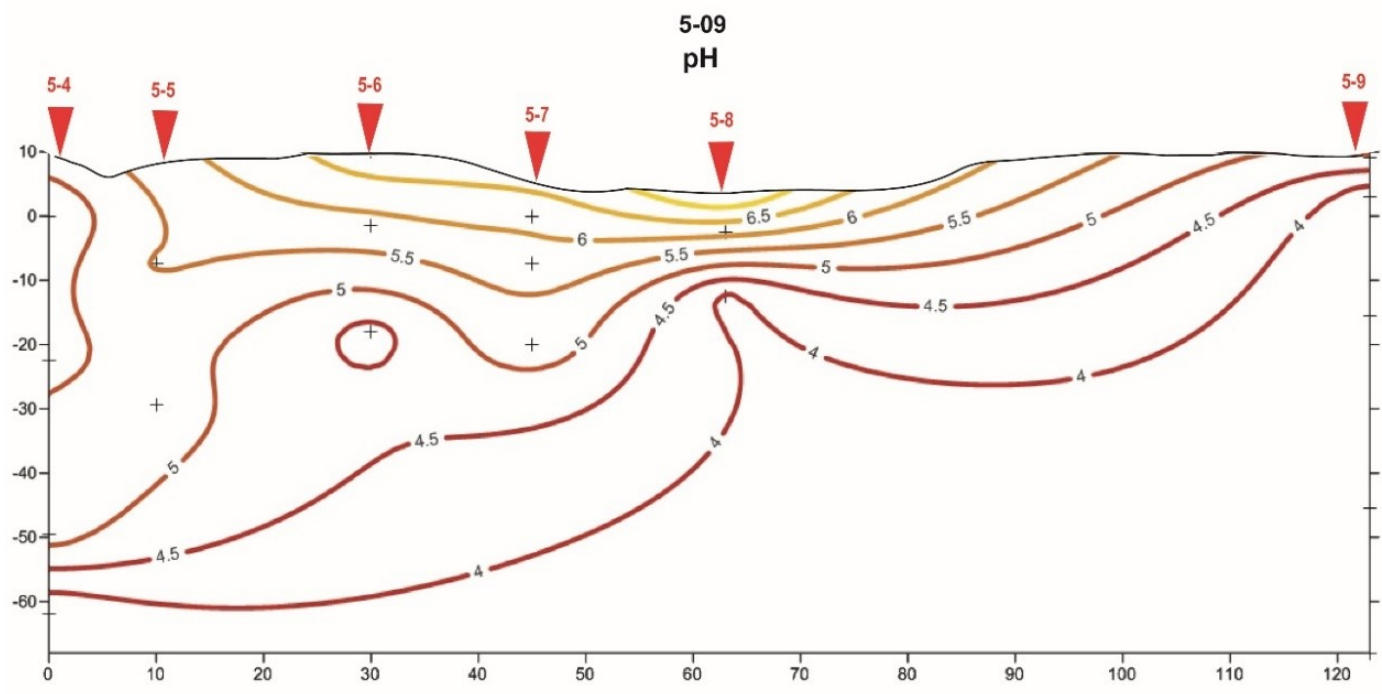

Figure 12. Changes in $\mathrm{pH}$ values in peat-podzolic $(5-4,5-5,5-6)$ and peat swamp upland soils $(5-7,5-8)$ in case of the pipeline accident.

\section{CONCLUSIONS}

The studies have identified some similarities and differences in the distribution of pollutants in peatpodzolic and peat swamp soils of the middle taiga of Western Siberia.

1.Migration and accumulation of bituminous substances in organogenic soils depends to a greater extend on the microrelief of swamps and the direction of swamp waters movement. In ridgehollow swamps pollution differs by a greater spatial distribution than in ryam swamps. Ridges are mechanical barriers to pollutant migration. In ryam swamps, which receive atmospheric precipitation, areas of maximum pollution shift to lower horizons. 2.In peat-podzolic soils contamination with bituminouis substances is confined to the peat horizon. The surface slope plays an important role in lateral distribution of pollutants.

3.For any type of contamination, the content of chlorine and sodium in the composition of ion-salt complex increases very significantly in all types of soils. Differences in chlorine and sodium distribution are associated with the presence and thickness of organogenic horizons and degree of hydromorphizm. In ridge-hollow swamps chlorine spreads for greater distances from the source of exposure (up to $100 \mathrm{~m}$ ) than sodium (up to $50 \mathrm{~m}$ ). In ryam swamps, differences in chlorine and sodium distribution are smoothed out $(20 \mathrm{~m}$ and 30 
m-respectively). In peat-podzolic soils, the distribution of chlorine is correspondent to sodium distribution in mineral horizons and in organogenic soils chlorine spreads over greater distances than sodium ( $30 \mathrm{~m}$ and $35 \mathrm{~m}$ - respectively).

4.Transformation of alkaline-acid properties is associated with the alkalization of acidic and mildly acidic organogenic and mineral soils under different kinds of impact. In swamp soils alkalization is more significant (up to 6.5-7.0) than in soils of automorphic compositions (up to 6.0). The identified patterns in the geochemical and microbiological transformation of soils of the middle taiga of Western Siberia under the impact of technogenic hydrocarbons and readily soluble salts must be considered when planning works of EEOS (elimination of emergency oil spills), because it is the consideration of differences in the nature of the impact on different soils that will help increase their economic benefit.

\section{REFERENCES}

[1] Arinushkina E. V., A Manual of Chemical Analysis. Izd. Mosk. Gos. Univ., Moscow, 1970 [in Russian]

[2] Buzmakov S. A., S. M. Kostarev Transformation of geosystems in the oil production areas / Izvestiya vuzov. Neft i gas. News of higher education ..., 2004

[3] IUSS Working Group WRB, 2015. World Reference Base for Soil Resources 2014, update 2015. An international soil classification system for naming soils and creating legends for soil maps. World Soil Resources Reports No. 106 (2014). https: //doi.org/10.1017/S0014479706394902.

[4] Glazovskaya M. A., Methodological Bases of Assessment of Ecological-Geochemical Tolerance of Soils to Technogenic Influences. Mosk. Gos. Univ., Moscow, 1997 [in Russian]

[5] Pikovskii Yu. I., Natural Technogenic Streams of Hydrocarbons in the Environment. Mosk. Gos. Univ., Moscow, 1993 [in Russian]

[6] Solntseva N. P., Oil Recovery and the Geochemistry of Natural Landscapes. Izd. Mosk. Gos. Univ., Moscow, 1998 [in Russian]. 